\title{
A Remedial Control Scheme Protects Agairst Transient Instabilities Based on Phasor Measurement Units (PMUs) -A Case Study
}

\author{
Yi-Jen Wang
Chih-Wen Liu
Department of Electrical Engineering
National Taiwan University
Taipei, Taiwan

\begin{abstract}
This paper proposes a fast remedial control scheme to prevent power system blackout due to the severe fault at the major EHV transmission line, which transfers large power between areas. We use PMU's to monitor the generators and the major EHV transmission lines of a power system, and apply fault detection/location system to precisely detect/locate fault for initiating remedial control actions to avoid a sequence of relay trip events whenever necessary. Then using real-time phasor measurements estimates the parameters of OMIB. The remedial control actions consist of load shedding and fast-valve control of turbines. The strategy for determining the timing and amount of remedial control actions is a proposed line-based equal area criterion.

The proposed scheme is tested with Taipower system, which experienced a severe fault at a major EHV tie-line which carried more than $1500 \mathrm{MW}$ and caused a successive relay trips resulting in system north and center area blackout on July 29, 1999 (729 event). Almost total $83 \%$ consumers had an interruption in 729 event. We simulate the scenario of 729 -event and the proposed scheme using PSS/E-24 simulator program. Encouraging results are obtained.
\end{abstract}

Keywords: PMU, Blackout, Remedial Control, Transient Stability.

\section{I.INTRODUCTION}

The power system in Taiwan is a longitudinal one with three major areas on the island, namely, North, Center, and South, connected together by a number of $345 \mathrm{kV}$ transmission lines.Its structure is illustrated in Figure 1. Since major load centers are located in the north and most generating plants are in the central and southern areas, significant power transfers from central area and southern area to the northern area have been experienced in the past few years.

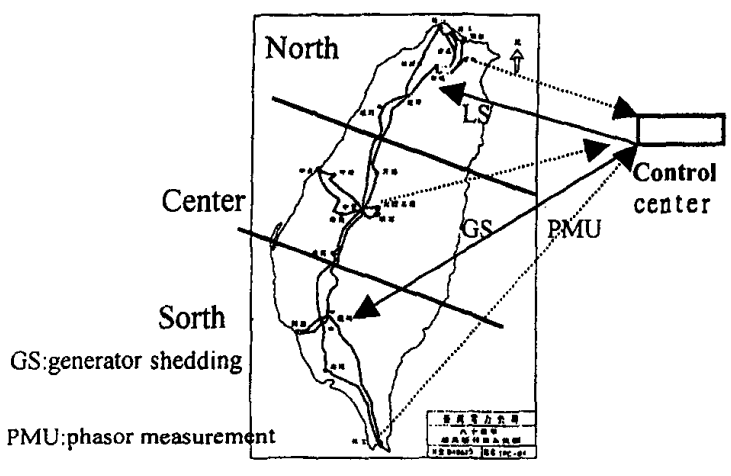

LS:load shedding

Figure 1: Structure of the Taiwan $345 \mathrm{kV}$ system

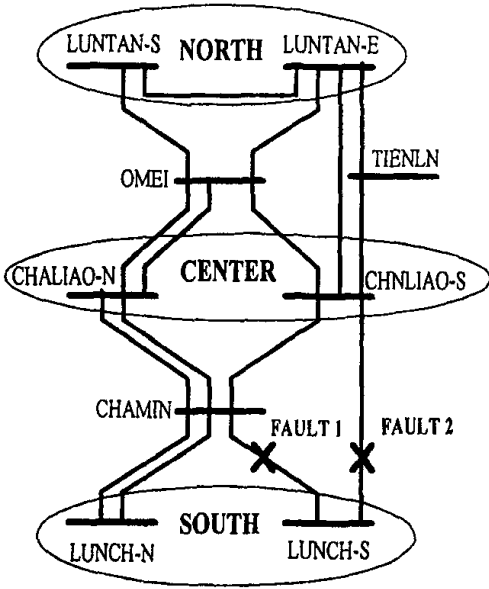

Figure 2 :One-line diagram of main $345 \mathrm{kV}$ transmission systems (including 729-event fault location)

Figure 2 depicts a one-line diagram of the main $345 \mathrm{kV}$ transmission systems connecting the North, the Center and the Sourth. The surplus power in the central and southern areas is transmitted to the North through two parallel circuits. On July 29, 1999, a severe fault occurred on the major $345 \mathrm{kV}$ tie-line between the south area and the center.area, which carried more than $1500 \mathrm{MW}$ and caused a successive relay trips resulting in system north and center area blackout (729-event). Almost total $83 \%$ consumers had an interruption in 729-event, and affected more people and extended over a wider geographic area than any previous outages. We proposed a fast remedial control scheme to prevent power system blackout due to the severe fault at major EHV transmission line, which transfer large power between areas.

\section{THE REMEDIAL CONTROL SCHEME}

The remedial control scheme presented in figure 1.It uses a decision-making center called "control center", which has a global view of the power system operation with real-time knowledge of phase angles over all the areas. We use PMU's to monitor the generators and the major EHV transmission lines of a power system, and applies fault detection/location system [16] to precisely detect/locate fault for initiating remedial control actions to avoid a sequence of relay trip events whenever necessary. The remedial control actions consist of load shedding and fastvalve control of turbines. The strategy for determining the 
timing and amount of remedial control actions is a proposed line-based equal area criterion (line-based EAC).

\section{A.Estimating the Parameters $\mathrm{P}, \mathrm{B}$ and $\mathrm{C}$ of One-Machine- Infinite-Bus Sysem}

In the classical models of multimachine system, it is assumed that fior an assigned fault, the multimachine system is decomposed into two subsets: (1) the critical cluster of machine(s) B, and (2) the remaining machines A (Figure 2). The former is responsible for system separation when it arises. Then the two subset are transformed into two

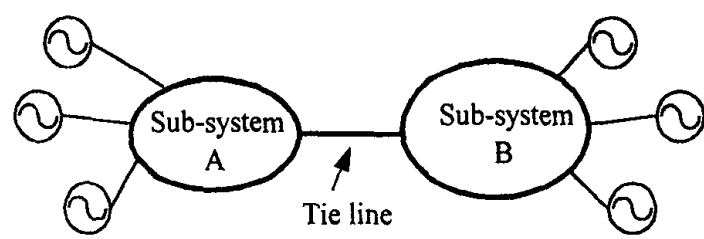

Figure 2 Group of generators swinging coherently

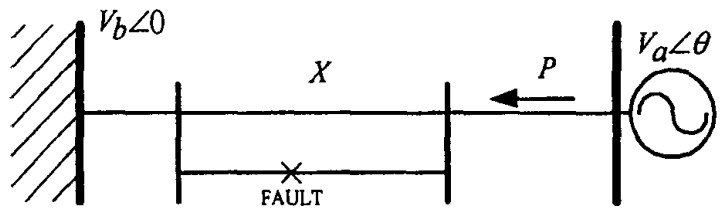

Figure 3. A generator and infinite bus system.

equivalent machines, modeled within their corresponding frame of partial center of angle (COA), and with the assumption of strong coherency of machines in each cluster, the two-machine equivalent system is futher reduced to an One-Machine-Infinite-Bus (OMIB) system which is giving by:

$\ddot{\delta}=P+B \cos (\delta)+C \sin (\delta)$

Our task is to estimate the parameters of (1) where $\delta$ may represent the angle difference between two machines, one in each group, or else the angle difference between two partial COA's of the two groups. Since the estimation relies on measuring $\delta$, we require any generator angle appearing in the partial COA expressions to be measurable. Let $\delta(m \Delta t), \mathrm{m}=0, \ldots . ., \mathrm{N}$ be the measurements of $\delta$, where $\Delta t$ is the sampling interval. We assume, without loss of generality, that the first sample occurs at time $t=0$ for the sake of notation. The second derivative $\ddot{\delta}(t)$ can be approximated by

$\ddot{\delta}(m \Delta t) \approx \frac{\delta((m+1) \Delta t)-2 \delta(m \Delta t)+\delta((m-1) \Delta t)}{(\Delta t)^{2}}$ $\mathrm{m}=1, \ldots \ldots, \mathrm{N}-1$

We seek to estimate parameters $\mathrm{P}, \mathrm{B}$ and $\mathrm{C}$ such that the measurements $\delta(m \Delta t)$ fit the model in an optimal way. Consider the error function

$e(t)=\ddot{\delta}(t)-P-B \cos \delta(t)-C \sin \delta(t)$

where $\mathrm{e}(\mathrm{t})$ can be thought of as a function of the parameters $\mathrm{P}, \mathrm{B}$ and $\mathrm{C}$. A good estimation of $\mathrm{P}, \mathrm{B}$ and $\mathrm{C}$, based on the samples $\delta(m \Delta t)$, should make the error function $e(m \Delta t)$ small. One way to achieve this is by least squares, i.e. by minimizing

$$
P, B, C \sum_{m=1}^{N-1} e^{2}(m \Delta t)
$$

The summation ranges from 1 to $\mathrm{N}-1$, because $\ddot{\delta}(0)$ and $\ddot{\delta}(N \Delta t)$ are not available.

$$
A=\left[\begin{array}{ccc}
1 & \cos \delta(\Delta t) & \sin \delta(\Delta t) \\
\cdot & \cdot & \cdot \\
\cdot & \cdot & \cdot \\
\cdot & \cdot & \cdot \\
1 & \cos \delta((N-1) \Delta t) & \sin \delta((N-1) \Delta t)
\end{array}\right], \quad b=\left[\begin{array}{c}
\ddot{\delta}(\Delta t) \\
\cdot \\
\cdot \\
\cdot \\
\ddot{\delta}((N-1) \Delta t)
\end{array}\right] \text {. }
$$

Then, the least square estimate of parameters $P, B$, and $C$ is

$$
\left[\begin{array}{l}
P \\
B \\
C
\end{array}\right]=\left(A^{T} A\right)^{-1} A^{T} b
$$

\section{B.The line-based EAC concept for OMIB}

In a OMIB system if a fault or disturbance causes the machine to start swinging with respect to an infinite bus, EAC can determine the stability of the system under transient conditions without solving the swing equation. Power angle curves are used to analyze the physical conditions before, during and after a fault. The EAC method can decide the stability of the systems. Our purpose is to protect the EHV-tie line far from cascade faults, so we use the line power flow limit, which is setted by relay to modify the EAC methods. The decelerating area will decrease by the line power limit like Figure 4 . To avoid a sequence of EHV tie-line's relay trip events, the remedial control actions consist of load shedding and fast-valve control of turbines to modify the Pm like figure 4. The strategy for determining 


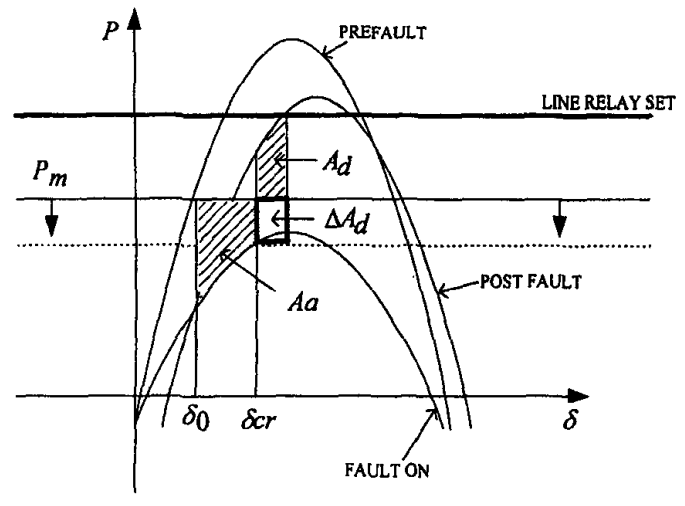

Figure 4 The concept of line-base EDC method

the amount of remedial control actions is by the proposed line-based equal area criterion.

\section{III.SIMULATION RESULTS}

A System Description

The system under study is the Taiwan power system in the year 1999 using PSS/E-24 simulator program. The peak power flows established by system planners at TPC. Table 1 summary is a generation and load for the load patterns under study.

It is observed from Table 1 that the deficit power in the northern area ( $4487 \mathrm{MW})$ must be supplied from the generators in the central and southern areas through the North-Center $345 \mathrm{kV}$ and $161 \mathrm{kV}$ lines. Since most of the inter-area power flows are transmitted through $345 \mathrm{kV}$ lines, how to protect these EHV tie-lines will be of major concern in this work.

Table 1 AREA GENERATIONS AND LOAD (MW)

\begin{tabular}{|c|c|c|c|}
\hline & North & Center & South \\
\hline Generation & 6310.0 & 8941.0 & 9335.0 \\
\hline Load + loss & 10797.1 & 6447.3 & 7092.5 \\
\hline Surplus power & -4487.1 & 2493.7 & 2242.5 \\
\hline
\end{tabular}

*generations and loads in the eastern area are not included

\section{B. Test Results}

To verify the proposed method, simulations are performed using the TPC systems with ZIP load models[2].First we simulate the 729 events which has two faults at $t=0$ and $t=1.632$ seconds on the same circuit from sourth area to ceter area in figure 2.The result is in figure 5 and 6 . We can see that the system is unstable like 729-event. Secondly, we use open loop control to reduce the transfer power at every time faut occurs. The action consists of load shedding and fast-valve control of turbines.The amount of remedial control is the prefault line power. Total are triped and shedded about $1484 \mathrm{MW}$. The results are shown in figure 7 and 8. Finally, we use the proposed line-based equal area criterion, and action is taken at second fault. The remedial action amount is $1133 \mathrm{MW}$. The results are shown in figure 9 and 10.

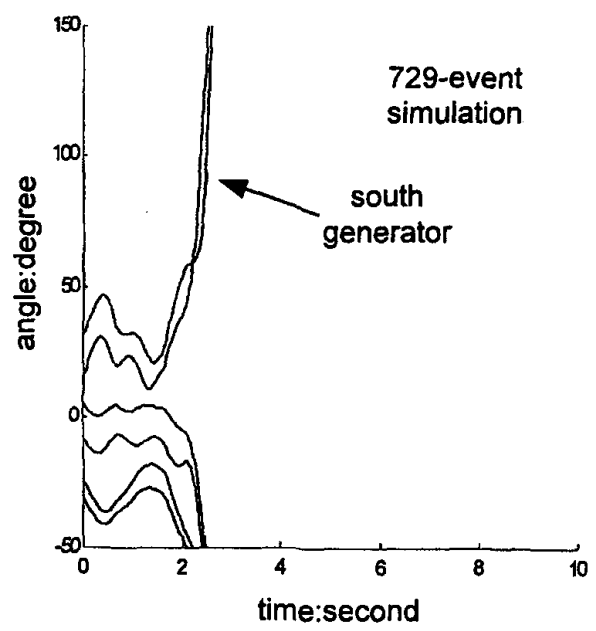

Figure 5 729-event generator angles

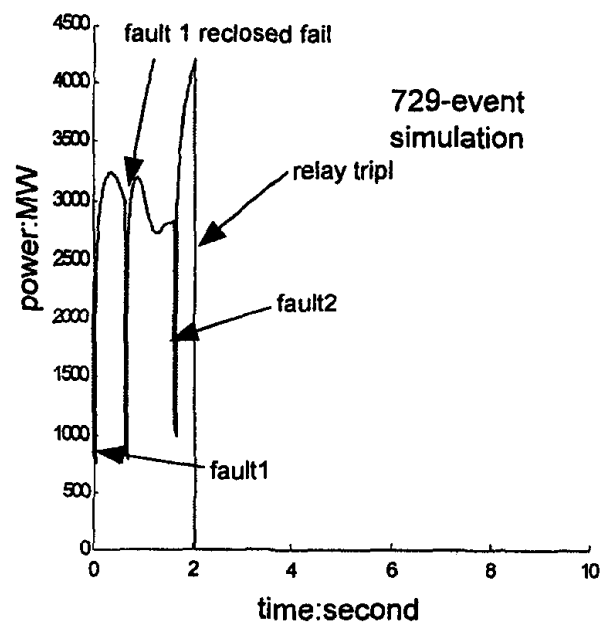

Figure 6 729-event EHV tie line power

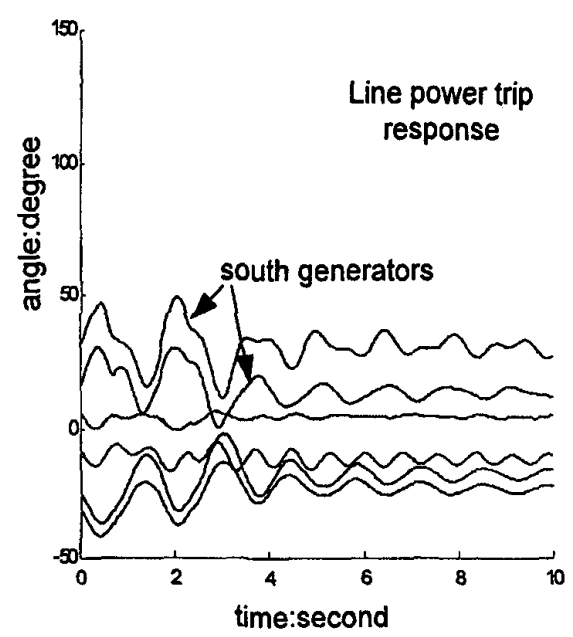

Figure 7 Line power flow trip method response 


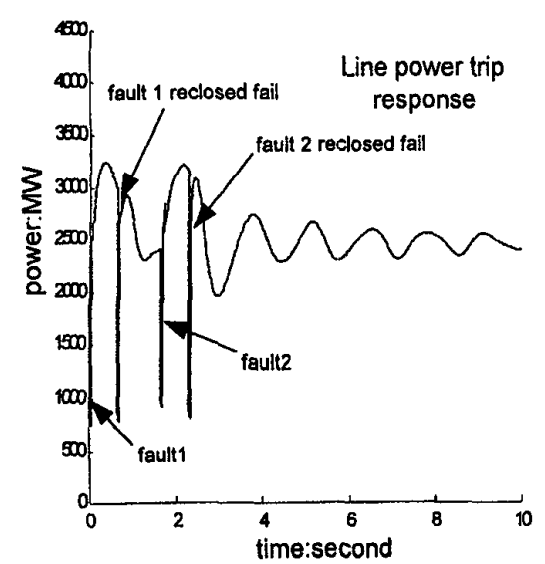

Figure 8 Line power flow trip method response

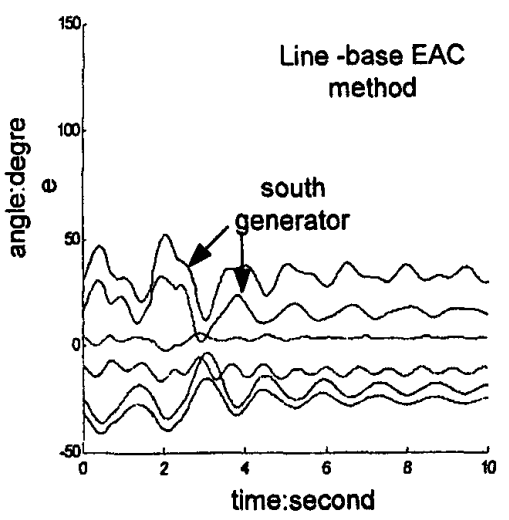

Figure 9 Line-base EAC method response

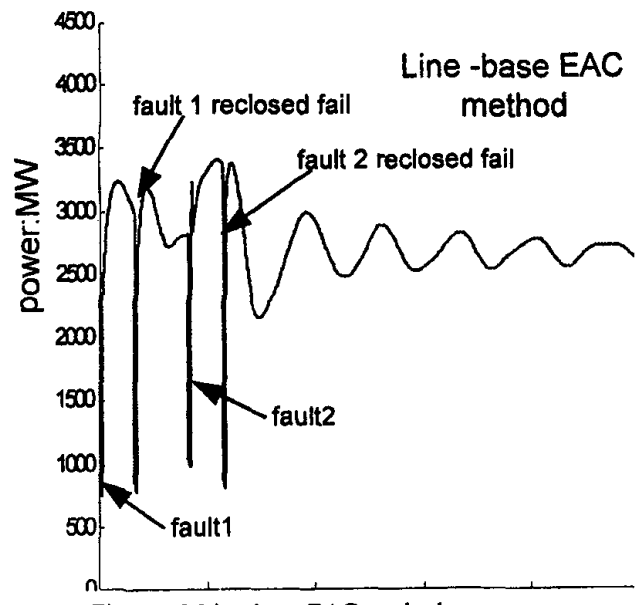

Figure 10 Line-base EAC method response

\section{IV.CONCLUSION}

This paper proposes a fast remedial control scheme to prevent power system blackout due to a sequence of relay trip events. We use PMU's to monitor the generators and the major EHV transmission lines of a power system, and applies fault detection/location system to precisely detect/locate fault for initiating remedial control actions. Then using real-time phasor measurements estimates the parameters of OMIB. The remedial control actions consist of load shedding and fast-valve control of turbines. The strategy for determining the amount of remedial control actions is a proposed line-based equal area criterion for OMIB. Encouraging results are obtained.

\section{V.REFERENCES}

[1] Faucon, O., and Dousset, L. "Coordinated Defense Plan Protects Against transient Instabilities." IEEE Computer Applications in Power, July 1997, pp.22-26.

(2) Kao,W.-S.,Lin, C.-J. and C.-T.Huang,"Comparison of Simulated Power System Dynamic Applying Various Load Models with Actual Recorded Data", IEEE Trans. on Power Systems, vol.9, No.I, pp.248-254, February 1994

[3] Minakawa, T., Sato, M., Ichikawa, Y, and Ishihara, Y. "A New Method for Detecting Loss of Synchronism Using Power and Current Measured on a Line." PE-045-PWRD-0-03-1998, pp.1-6.

[4] P.M. Anderson, and A.A. Fouad, Power System Control and Stability, lowa State University Press, Ames, 1977.

[5] V. Centeno et al., "Adaptive Out-of-Step Relaying Using Phasor Measurement Techniques", IEEE Computer Applications in Power, vol.6, No.4, pp.12-17,1993.

[6] $\mathrm{Ph}$. Denys et al., "Measurement of Voltage Phase for the French Future Defence Plan Against Losses of Synchronism", IEEE Trans. on PWRD, PWRD-7, No.1, pp.62-69,1992.

[7] A.A. Fouad et. al., "Dynamic Security Assessment Practices in North America", IEEE Trans. on Power Systems, PWRS-3, No.3, pp.13101321, 1988.

[8] C.-W.Liu and J.S.Thorp, "Application of Synchronized Phasor Measurements to Real-Time Transient Stability Prediction", IEE Proc.-Gener. Transm. Distrib., vol.142, No.4, pp.355-360, 1995.

[9] A.G. Phadke and J.S. Thorp, Computer Relaying for Power Systems, John Wiley and Sons Inc., New York, 1988.

[10] A.G. Phadke, "Synchronized Phasor Measurements in Power Systems", IEEE Computer Applications in Power, vol.6, No.2, pp.10-15, 1993.

[11] A.G. Phadke et al., "Synchronized Sampling and Phasor Measurements for Relaying and Control", IEEE PES Winter Meeting, Columbus, Ohio, Feb.1993(93 WM 039-8-PWRD).

[12] S. Rovnyak, C.-W. Liu, J.Lu, W. Ma and J. Thorp, "Predicting future Behavior of Transient Events Rapidly Enough to Evaluate Remedial Control Options in Real-Time", IEEE Trans, on Power Systems, vol.10, No.3, pp.1195-1203, 1995.

[13] C.W. Taylor, J.M. Haner, L.A.Hill, W.A. Mittelstadt, and R.L. Cresap, "A New Out-of-Step Relay with Rate of Change of Apparent Resistance Augmentation", IEEE Trans. on Power Apparalus and Systems, vol.PAS-102, No.3, pp.631-639, March 1983.

[14] J.S. Thorp, A.G. Phadke, S.H. Horowitz and M.M. Begovic, "Some Applications of Phasor Measurements to Adaptive Protection", IEEE Tran. on Power Systems, vol.3, No.2 pp.791.798, May 1988. 
[15] S. Rovnyak, S. Kretsinger, J. Thorp, and D. Brown, "Decision Trees for Real-Time Transient Stability Prediction", IEEE Trans. on Power Systems, vol.9,No.3,pp. 1417-1426, Aug. 1994

[16] J. -A. Jiang, J. -Z. Yang, Y. -H. Lin, C. -W. Liu and J. -C. Ma, "An Adaptive PMU Based Fault Detection/Location Technique for Transmission Lines, Part I: Theory and Algorithms," IEEE Transactions on Power Delivery, PE-017 PRD (09-99).

\section{BIOGRAPHIES}

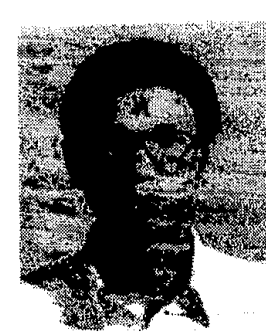

Yi-Jen Wang was born in Taiwan in 1961. He received his B.S. degree in electrical engineering from National Taiwan University of Science and Technology in 1986, M.S. degree in electrical engineering from National Taiwan University in $1990 . \mathrm{He}$ is currently working toward his Ph.D. degree at National Taiwan University. His research interests include power system analysis and application of synchronized phasor measurements to enchance power system transient stability.

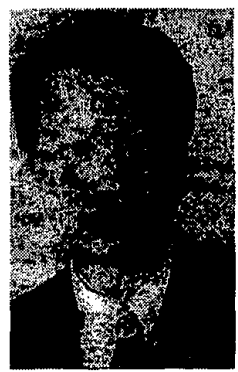

Chih-Wen Liu was born in Taiwan in 1964 He received the B.S. degree in Electrical Engineering from National Taiwan University in 1987, and M.S. and Ph.D. degrees in electrical engineering from Cornell University in 1992 and 1994. Since 1994, he has been with National Taiwan University, where he is associate professor of electrical engineering. He is a member of the IEEE and serves as a reviewer for IEEE Transactions on Circuits and Systems, Part I. His main research area is in application of computer technology to power system monitoring, operation, protection and control. His other research interests include GPS time transfer and chaotic dynamics and their application to system problems.

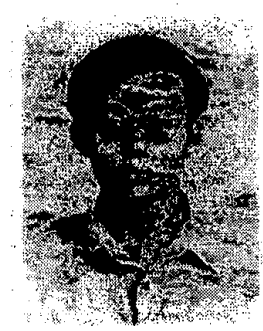

Len-Dar Sue was born in Changhua, Taiwan, in 1976. He received his B.S degree in electrical engineering from National Taipei University of Technology in 1999 and is currently working on M.S. degree at National Taiwan University, Taipei, Taiwan.

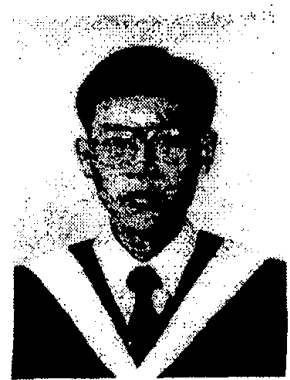

Wen-Kuang Liu was born in Kaohsiung, Taiwan, in 1972. He received his B.S degree in electrical engineering from National Taipei University of Technology in 1998 and is currently working on M.S. degree at National Taiwan University, Taipei, Taiwan. 